\title{
GRACE: spreading knowledge about community-acquired pneumonia
}

The European Respiratory Society (ERS) is

commencing a new exciting adventure in the educational field. Our Society, in collaboration with the European Society of Clinical Microbiology and Infectious Diseases (ESCMID), has joined the GRACE Network of Excellence, which has recently been funded by the European Community with a grant of $€ 11,500,000$.

GRACE is a Network of Excellence focusing on the complex and controversial field of community-acquired lower respiratory tract infections (LRTIS), which is one of the leading rea-

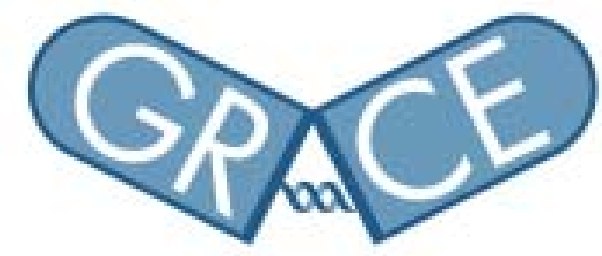

Genomics to cambat Resistonce agains Antibicica in Community ocquired LRTI in Europe
The two Societies have already started a fruitful collaboration in the educational field. The ERS School and the ERS Assembly 10 (Respiratory Infections), in collaboration with ESCMID, have already organised two external seminars on tuberculosis in the Baltic republics: one which took place in Riga (Latvia) in June 2005; and one which will take place in Tallin (Estonia) in June 2006. The new guidelines for the management of adults with LRTIs, which were recently published in the European Respiratory Journal [1], are another demonstration of the great value of the joint efforts of the two Societies.

GRACE will be an excellent opportunity for the two Societies to improve their collaboration not only in the educational field but also in the "European management" of infectious diseases.

A meeting and press conference to officially launch the GRACE project was held in Brussels on

\section{F. Blasi $i^{1}$ \\ R. Finch ${ }^{2}$ \\ P.L. Haslam ${ }^{3}$}

${ }^{1}$ Institute of Respiratory Diseases, University of Milan, IRCCS Ospedale Maggiore Fondazione Policlinico, Milan, Italy. 2University of Nottingham, Nottingham, UK. ${ }^{3}$ ERS School Chair \& Chief Editor of Breathe, Imperial College and Royal Brompton Hospital, London, UK. sons for seeking medical care. The large and IRTIs accounts for a major part of the community burden of antibiotic use and contributes dramatically to the rising prevalence of resistance among major human pathogens. The overall objective of GRACE is to combat antimicrobial resistance through integrating centres of research excellence and exploiting genomics in the investigation of community-acquired LRTIs. Microbial and human genomics will be integrated with health sciences research consisting of clinical observational and intervention studies. Health education and health economics will also play an important part in spreading knowledge and to specifically change practice in managing community-acquired LRTIs.

The ERS, in partnership with ESCMID, is responsible for organising the educational work package for the Network. A budget of $€ 500,000$ will be spread over 5 years to organise professional education, including conventional courses and workshops, web-based teaching, practical courses and durable educational material to disseminate the excellence of the programme.

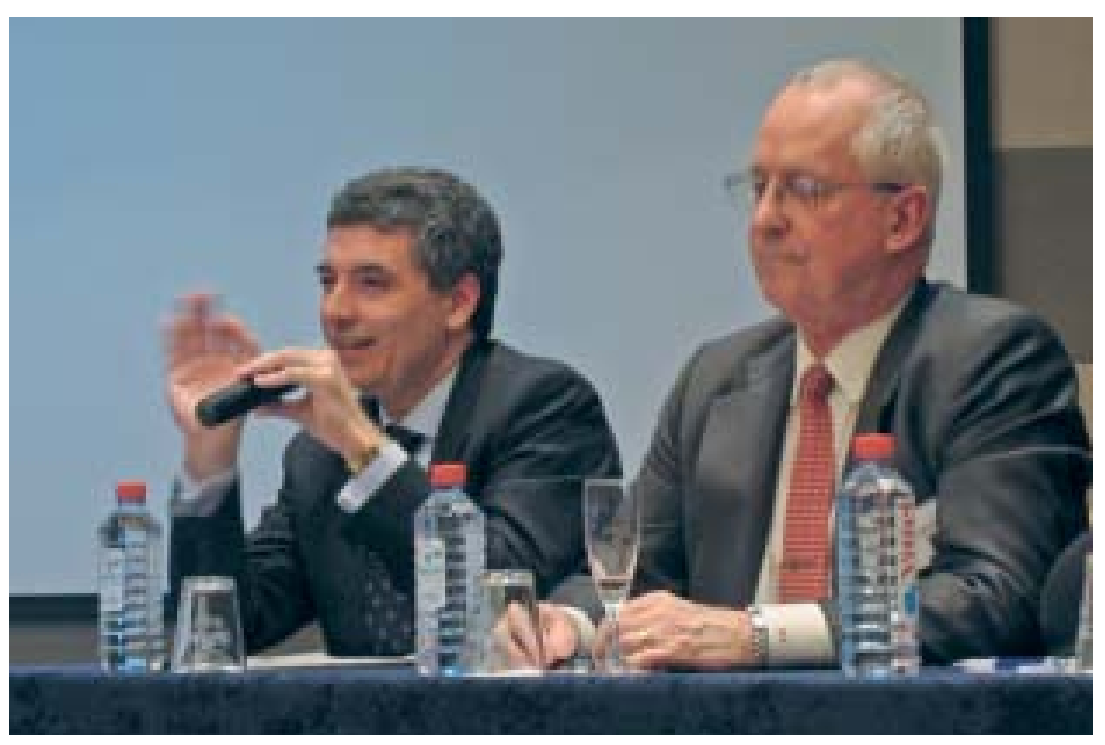




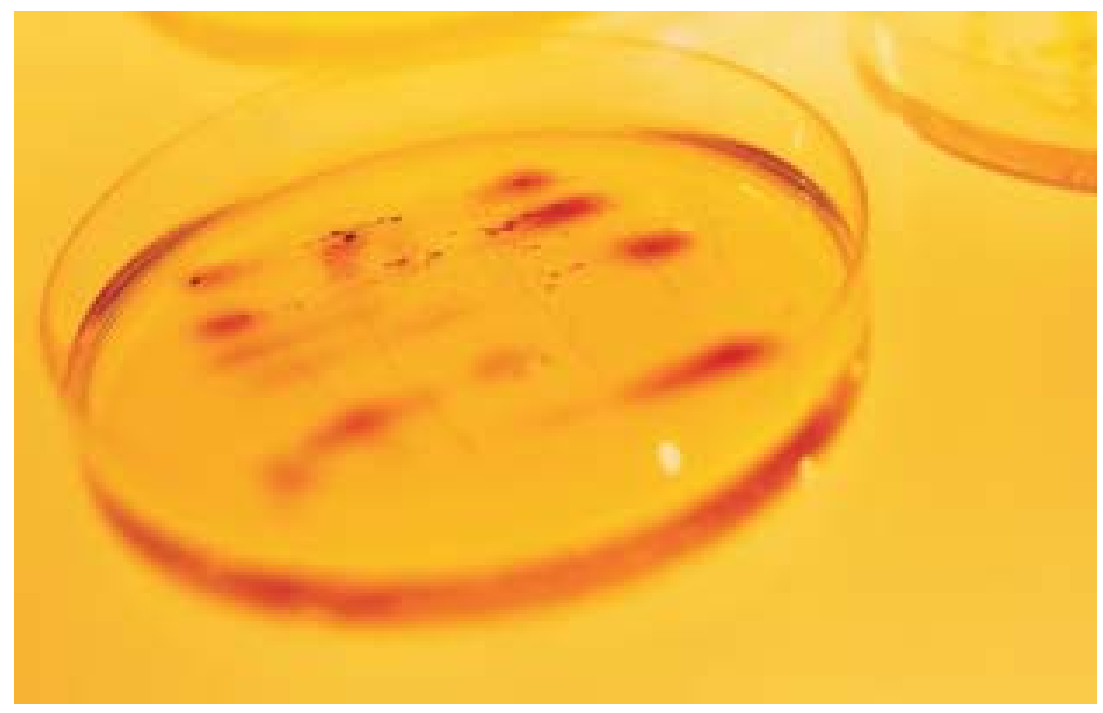

March 16-17, 2006, involving representatives from DG Research and the leaders of all the research and education work packages. During the meeting, the representatives of the ERS and ESCMID met to further develop the overall strategy to integrate research and education within the context of community-acquired LRTI into a sustainable platform for the training of clinicians and scientists both within and beyond the GRACE Network. The two co-leaders of the educational work package will be Roger Finch (ESCMID) and Francesco Blasi (ERS Head of Assembly 10). The ERS School will be deeply involved in the organisation of Postgraduate courses and technical and non-technical workshops. It was agreed to establish a Curriculum and Education Committee for this work package comprising the following members: Francesco Blasi (ERS), Jean-Luc Eiselé (ERS), Javier Garau (ESCMID), Patricia L. Haslam (ERS), Peter Schoch (ESCMID) and Roger Finch (ESCMID).

The activities for the educational work package will start on September 2, 2006 in Munich at the annual ERS Congress, with a full-day programme of two postgraduate courses called "GRACE Postgraduate courses". The morning course will be on the aetiology, diagnosis and management of pneumonia, and the afternoon course on the epidemiology and clinical approach to antibiotic resistance. These will provide an excellent start to this new venture for all those interested.

\section{References}

1. Woodhead M, Blasi F, Ewig S, et al. Guidelines for the management of adult lower respiratory tract infections. Eur Respir J 2005; 26: 1138-1180.

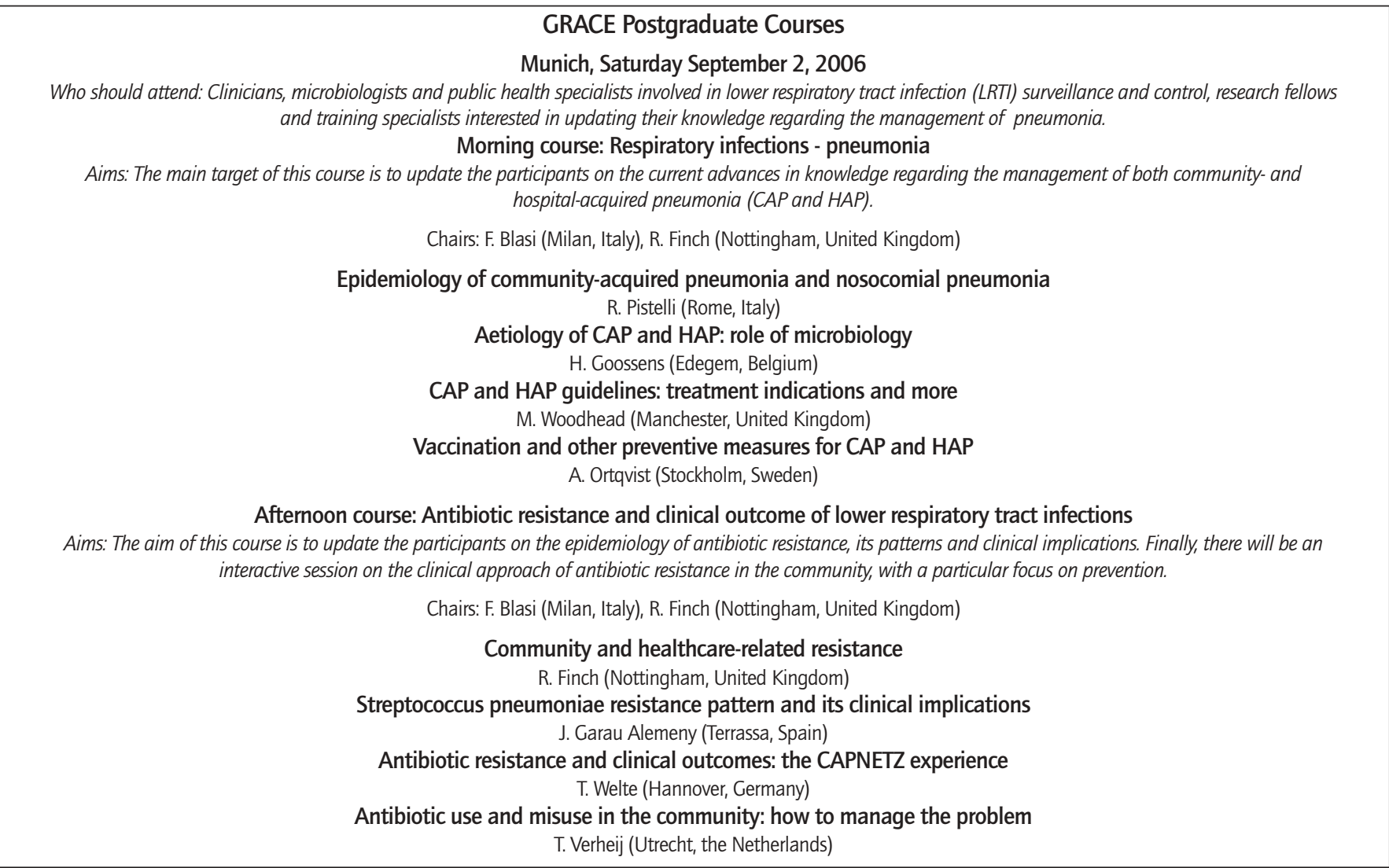

